\title{
Host-guest complexes of some cucurbit[n]urils with the hydrochloride salts of some imidazole derivatives
}

\author{
Yan Feng $\cdot$ Sai-Feng Xue $\cdot$ Zhi-Fang Fan • \\ Yun-Qian Zhang · Qian-Jiang Zhu • \\ Zhu Tao
}

Published online: 27 February 2009

(C) Springer Science+Business Media B.V. 2009

\section{Erratum to: J Incl Phenom Macrocycl Chem DOI 10.1007/s10847-009-9544-7}

Unfortunately, the first reference in the reference list at the end of this paper was lost during its preparation. It should read:

1. Freeman, W.A., Mock, W.L., Shih, N.Y.: Cucurbituril. J. Am. Chem. Soc. 103, 7367-7368 (1981). doi: 10.1021/ ja00414a070
Because of this omission one number should be added to all other references in the reference list. Reference 36 (Tao et al. 2004) is then referred to in the second sentence of the third paragraph of the section entitled "Crystal structure determination of the inclusion complex TMeQ [6]-g2 and g3 . $\mathrm{HCl}$ ".

The online version of the original article can be found under doi:10.1007/s10847-009-9544-7. 